\title{
Response to the Correct Usage of the Term "off- Label" in the Context of Corneal Cross-Linking [Response To Letter]
}

\section{Manoj Motwani}

Motwani LASIK Institute, San Diego, CA, 92121, USA
Correspondence: Manoj Motwani Motwani LASIK Institute, 4520 Executive Dr., Suite 230, San Diego, CA, 9212I, USA

Tel +I 858 554-0008

Email drmmlj@gmail.com

\section{Dear editor}

Although we certainly understand Dr. Katz's position as chief medical officer of Glaukos (who own Avedro) (Glaukos, Inc.; San Clemente, CA), we must disagree with his assessment of the off-label nature of the procedure used in this article. The initial letter by Dr. Katz was also followed by a subsequent letter by Dr. Shamie, another consultant for Glaukos. We will address both letters in this one. First of all, Glaukos/Avedro did not obtain FDA approval for use of cross-linking after treatment with topographic guided ablation. By its nature, this entire procedure is off-label.

To get to the heart of the matter concerning Drs. Katz and Shamie, Avedro obtained FDA approval for the use of an ultraviolet A light source providing a set amount of UV energy to a cornea that had been saturated with riboflavin. ${ }^{4}$ This combination catalyzes the corneal cross-linking necessary to strengthen ectatic corneas, and in approving this the FDA agreed with the rest of the world that has already been providing treatment for keratoconus/corneal ectasia with this procedure. Our goal was to utilize this procedure in the best possible form for the best possible results for patients undergoing treatment with topographic guided ablation and CXL with this very debilitating disease.

Ultraviolet light in the form necessary for cross-linking is not difficult to generate, nor is it regulated by the FDA. A person being out on a sunny San Diego afternoon likely will get as much UV exposure as in a cross-linking procedure, and obviously there is no FDA approval necessary for that. The letter by Dr. Shamie implies that UV light parameters were not listed, they were actually in the paper. The fact is that these parameters have long been set to deliver a set amount of UV light to the cornea, with UV light intensity increasing to accomodate for shorter treatment times but always designed to deliver the same amount of UV irradiation. This was to ensure sufficent cross-linking while minimizing safety risk to endothelial cells. The parameters listed in this manuscript provide the correct amount of UV irradiation to the cornea, the same amount as the irradiation by the Glaukos lamp for their 30 minute protocol. Riboflavin being a naturally occurring vitamin also does not have its use regulated by the FDA. Furthermore, a note on pharmaceutical grade riboflavin: compounding pharmacies are licensed and certified to produce all forms of "pharmaceutical grade" medical compounds for the safe treatment of patients. 
What Avedro obtained was the approval of the combination of the two causing the catalytic reaction in corneal cross-linking to strengthen an ectatic cornea. If we do not use Avedro's particular riboflavin combination, nor do we use Avedro's set protocol for longer exposure time with lower energy, but we are still catalyzing the same reaction with riboflavin and the set amount of UV light then we are performing the same catalyzed procedure, then we consider it an off-label procedure. The total amount of UV light exposure must be the same whether a 30-min, 15min, 6-min or 3-min protocol is used according to the set internationally accepted protocols. We chose the 15minute protocol specifically because it has been shown to be better for patients not only for simple comfort, but for epithelial healing and patient recovery. ${ }^{1-3}$ Furthermore in private discussion with Dr. Kanellopoulos, who created the Athens Protocol and is one of the foremost experts on this procedure, he relayed that in his experience the 15-minute protocol led to the best, most stable results in patients in the combined topographic guided ablation and corneal cross-linking Athens Protocol procedure, and also that his experience indicates riboflavin without dextran leads to the best results. Thereby we are utilizing what we consider the best form of corneal cross-linking when used in combination with topographic guided correction of the ectatic cornea.

We did approach Avedro executives in 2016 with these thoughts and were told that Avedro had no interest in supporting any studies, research or changes to its keratoconus protocol. They made it clear it was a financial decision, not a medical one. We would have happily worked with Avedro at that time as a partner for this particular procedure, but we understand that coporations necessarily have their own priorities.

Our work here, and this paper, only applies to this combined topographic guided ablation combined with corneal cross-linking procedure; we do not purport to extrapolate this to simple cross-linking procedures that Avedro does support.

Keratoconus is a serious, disabling disease that afflicts tens of thousands of people in the United States, and hundreds of thousands throughout the world. We as physicians must find the best possible treatments to help patients; it is our duty to use all the tools available in the best possible manner available to yield the best possible results for our patients.

\section{Disclosure}

Dr Manoj Motwani reports a patent issued (US patent nos. 10857032 and 10857033). The author reports no other conflicts of interest in this communication.

\section{References}

1. Wen D, Li Q, Song B, et al. Comparison of standard versus accelerated corneal collagen cross-linking for keratoconus: a meta-analysis. Invest Ophthalmol Vis Sci. 2018;59(10):3920. PMID: 30073363. doi:10.1167/ iovs.18-24656

2. Tomita M, Mita M, Huseynova T. Accelerated versus conventional corneal collagen crosslinking. J Cataract Refract Surg. 2014;40 (6):1013-1020. doi:10.1016/j.jcrs.2013.12.012

3. Kanellopoulos AJ. Long term results of a prospective randomized bilateral eye comparison trial of higher fluence, shorter duration ultraviolet A radiation, and riboflavin collagen cross linking for progressive keratoconus. Clin Ophthalmol. 2012;6:97-101. doi:10.2147/OPTH. S27170

4. Center for drug evaluation and research summary review of photrexa viscous and photrexa, and KXL system; July 29, 2015.

\section{Publish your work in this journal}

Clinical Ophthalmology is an international, peer-reviewed journal covering all subspecialties within ophthalmology. Key topics include: Optometry; Visual science; Pharmacology and drug therapy in eye diseases; Basic Sciences; Primary and Secondary eye care; Patient Safety and Quality of Care Improvements. This journal is indexed on PubMed

Submit your manuscript here: https://www.dovepress.com/clinical-ophthalmology-journal
Central and CAS, and is the official journal of The Society of Clinical Ophthalmology (SCO). The manuscript management system is completely online and includes a very quick and fair peer-review system, which is all easy to use. Visit http://www.dovepress.com/ testimonials.php to read real quotes from published authors. 